\title{
Identification of the Risk Factors for Recurrence of Stage III Colorectal Cancer
}

\author{
KAI NEKI, KEN ETO, MAKOTO KOSUGE, MASAHISA OHKUMA, DAISUKE ITO, \\ YASUHIRO TAKEDA, SAORI YATABE, HIROSHI SUGANO and KATSUHIKO YANAGA \\ Department of Surgery, The Jikei University School of Medicine, Tokyo, Japan
}

\begin{abstract}
Background/Aim: This study aimed to identify risk factors for recurrence of patients with stage III colorectal cancer by assessing clinicopathological features. Patients and Methods: The study included 231 patients with stage III colorectal cancer who underwent curative resection between 2006 and 2012 at the Department of Surgery of the Jikei University Hospital, Tokyo, Japan. Clinicopathological data of the patients were retrospectively evaluated. Results: The recurrence rate was $27.7 \%$ (64/231) in the study group. The univariate analysis for recurrence identified five risk factors: site of primary tumor (rectal cancer), surgical procedure (open surgery), preoperative serum CEA level (>5 $\mathrm{ng} / \mathrm{ml}$ ), preoperative serum CA19-9 level (>37 U/ml), and number of metastatic lymph nodes (over three metastases). The multivariate analysis for recurrence identified three risk factors: rectal cancer, preoperative serum CEA level $>5.0 \mathrm{ng} / \mathrm{ml} 95 \%$, and more than three metastatic lymph nodes. Conclusion: The risk factors for stage III colorectal cancer recurrence seem to be rectal cancer, preoperative serum CEA level $>5.0 \mathrm{ng} / \mathrm{ml}$, and more than three metastatic lymph nodes.
\end{abstract}

For stage III colon cancer, several randomized controlled trials (RCTs) have indicated that addition of oxaliplatin (L$\mathrm{OHP}$ ) to 5-fluorouracil (5-FU)+leucovorin (LV) as a postoperative adjuvant chemotherapy was effective for both suppression of recurrence and extension of survival time (15). Currently, a regimen with 5-FU+LV+L-OHP is positioned as a standard for postoperative adjuvant chemotherapy for stage III colon cancer. However, L-OHP has severe sideeffects such as peripheral neuropathy and leukopenia (3). In addition, L-OHP is expensive, and may not be cost-effective. For these reasons, L-OHP is not unusually recommended to

Correspondence to: Kai Neki, MD, Department of Surgery, The Jikei University School of Medicine, 3-25-8, Nishi-shinbashi, Minato-ku, Tokyo, 105-8461, Japan. Tel: +81 334331111 ext. 3401, Fax: +81354724140, e-mail: k-neki.05@jikei.ac.jp

Key Words: Risk factors, colorectal cancer, stage III. be included in postoperative adjuvant chemotherapy for stage III colorectal cancers in Japan. Furthermore, as postoperative adjuvant chemotherapy for colorectal cancer [except for rectum/below the peritoneal reflection $(\mathrm{Rb})$ rectal cancer], oral 5-FU+LV and capecitabine are not inferior to intravenous 5-FU+LV (6-8). Oral 5-FU+LV and capecitabine are less expensive and associated with fewer side-effects compared to intravenous 5-FU+LV. Therefore, clarifying the postoperative recurrence risk factors for stage III colorectal cancer may be able to select cases who benefit from L-OHP as adjuvant chemotherapy, and might reduce the use of not only L-OHP, but also 5-FU+LV. For such a purpose, here we report the high-risk factors for postoperative recurrence of stage III colorectal cancer in our hospital.

\section{Patients and Methods}

The subjects were 310 patients with stage III colorectal cancer who underwent curative resection between 2006 and 2012 at the Department of Surgery of the Jikei University Hospital, Tokyo, Japan. Of the 310 patients, we excluded four patients with insufficient histopathological factor descriptions and 75 patients for whom preoperative serum CA19-9 levels were not measured. Consequently, the remaining 231 patients were studied, of whom retrospectively retrieved data regarding their clinicopathologic characteristics, treatments, and clinical outcomes from their medical records were analyzed.

The variables studied consisted of the following patient factors: gender (male/female), age at surgery ( $\geq 75$ years/ $<75$ years), site of primary tumor (colon/rectum), surgical procedure (open/ laparoscopic), preoperative serum carcinoembryonic antigen (CEA) levels ( $\leq 5 \mathrm{ng} / \mathrm{ml} />5 \mathrm{ng} / \mathrm{ml}$ ), preoperative serum carbohydrate antigen 19-9 (CA19-9) levels ( $\leq 37 \mathrm{U} / \mathrm{ml} />37 \mathrm{U} / \mathrm{ml}$ ), postoperative adjuvant chemotherapy (yes/no), $\mathrm{T}$ category ( $\leq \mathrm{T} 3 / \mathrm{T} 4)$, histological differentiation (tubular adenocarcinoma/mucinous adenocarcinoma/ others), number of metastatic lymph nodes (over three metastases/equal or less than three metastases), venous invasion (yes/no) and lymphatic invasion (yes/no). Pathologic staging of the primary tumors was performed according to the Union for International Cancer Control TNM Classification of Malignant Tumors, seventh edition. Univariate Cox's proportional hazard (PH) regression analysis was performed to identify the risk factors for recurrence of patients with stage III colorectal cancer. Univariate 
analysis was performed using the Student's t-test and the Pearson's Chi-square test. All $p$-values were considered statistically significant when the associated probability was less than 0.05 . Variables with $p<0.05$ were included in the multiple Cox's PH regression model to identify independent risk factors associated with the incidence. The study protocol was reviewed and approved by the ethics committee and Institutional Review Board (27-283 8168).

\section{Results}

The patients' age ranged from 25 to 95 years, with a median age of 66 years. The overall recurrence rate was $27.7 \%$ $(64 / 231)$. The patients' characteristics are shown in Table I. The results of the univariate analysis of the background factors and recurrence in patients with stage III cancer are shown in Table II, and demonstrated five factors to be significant: surgical procedure (open surgery; $p=0.012$ ), site of primary tumor (rectal surgery; $p=0.010$ ), preoperative serum CEA levels ( $>5 \mathrm{ng} / \mathrm{ml} ; p=0.010$ ), preoperative serum CA19-9 levels ( $>37 \mathrm{U} / \mathrm{ml} ; p=0.009)$ and numbers of metastatic lymph nodes (over three metastases; $p<0.001$ ) (Table II). In the multivariate analysis, rectal cancer $(\mathrm{HR}=2.37,95 \% \mathrm{CI}=1.269-4.433, p=0.007)$, preoperative serum CEA level $>5.0 \mathrm{ng} / \mathrm{ml}(\mathrm{HR}=2.020,95 \% \mathrm{CI}=1.070$ $3.811, p=0.030$ ), and more than three metastatic lymph nodes $(\mathrm{HR}=2.890,95 \% \mathrm{CI}=1.479-5.646, p=0.002)$ were independent risk factors for recurrence (Table III).

\section{Discussion}

Currently, combination therapy of 5-FU/LV/L-OHP (FLOX, FOLFOX) is the standard regimen for adjuvant chemotherapy for stage III colorectal cancer. FOLFOX therapy has also been approved for insurance coverage in Japan as postoperative adjuvant chemotherapy for colorectal cancer. However, the inclusion of L-OHP remains controversial, because FOLFOX has serious side effects such as peripheral neuropathy, vasculitis and pancytopenia (3). In addition, FOLFOX is expensive. Nowadays, the surge in medical expenses is a national concern in Japan, and therefore reduction of medical expenses is very important for the Japanese medical economy.

According to the results of the Japanese Phase III study in the American Society of Clinical Oncology (ASCO) in 2012, for adjuvant chemotherapy for stage III colon cancer, the use of oral 5-FU was not inferior to FOLFOX (8). Based on this study, FOLFOX may be used as adjuvant chemotherapy for the high-risk group of stage III colorectal cancer. In the current study, we reviewed retrospectively the risk factors of recurrence of stage III colorectal cancer cases in our hospital.

In the current study, the overall recurrence rate was $28.1 \%$ $(65 / 231)$, which was slightly better than the aggregations (30.8\%) by the Japanese Society for Cancer of the Colon and Rectum (9).
Table I. Clinical characteristics of patients.

\begin{tabular}{|c|c|c|}
\hline Factor & Number & Rate $(\%)$ \\
\hline \multicolumn{3}{|l|}{ Age } \\
\hline$<75$ & 190 & 82.3 \\
\hline$\geq 75$ & 41 & 17.7 \\
\hline \multicolumn{3}{|l|}{ Gender } \\
\hline Male & 146 & 63.2 \\
\hline Female & 85 & 36.8 \\
\hline \multicolumn{3}{|c|}{ Site of primary tumor } \\
\hline Colon & 134 & 58 \\
\hline Rectum & 97 & 42 \\
\hline \multicolumn{3}{|c|}{ Surgical procedure } \\
\hline Open & 141 & 61 \\
\hline Laparoscopic & 90 & 39 \\
\hline \multicolumn{3}{|l|}{ CEA (ng/ml) } \\
\hline$\leq 5$ & 120 & 51.9 \\
\hline$>5$ & 111 & 48.1 \\
\hline \multicolumn{3}{|l|}{ CA19-9 (U/ml) } \\
\hline$\leq 37$ & 194 & 84 \\
\hline$>37$ & 37 & 16 \\
\hline \multicolumn{3}{|c|}{ Adjuvant chemotherapy } \\
\hline Yes & 175 & 75.8 \\
\hline No & 56 & 24.2 \\
\hline \multicolumn{3}{|l|}{$\mathrm{T}$ category } \\
\hline$\leq \mathrm{T} 3$ & 189 & 81.8 \\
\hline$>\mathrm{T} 3$ & 42 & 18.2 \\
\hline \multicolumn{3}{|c|}{ Histological differentiation } \\
\hline Tub & 207 & 89.6 \\
\hline Muc & 8 & 3.5 \\
\hline Others & 16 & 6.9 \\
\hline \multicolumn{3}{|c|}{ Number of metastatic lymph nodes } \\
\hline$\leq 3$ & 172 & 74.5 \\
\hline$>3$ & 59 & 25.5 \\
\hline \multicolumn{3}{|c|}{ Venous invasion } \\
\hline Yes & 176 & 76.2 \\
\hline No & 55 & 23.8 \\
\hline \multicolumn{3}{|c|}{ Lymphatic invasion } \\
\hline Yes & 158 & 68.4 \\
\hline No & 73 & 31.6 \\
\hline
\end{tabular}

CEA: Carcinoembryonic antigen; CA19-9: Carbohydrate antigen 19-9; Tub: tubular adenocarcinoma; Muc: mucinous adenocarcinoma.

For stage II colorectal cancer, several high recurrence risk factors have been defined. ASCO and the European Society for Medical Oncology have defined high-risk factors for recurrence of stage II colon cancer, which consist of T4, poorly differentiated or undifferentiated carcinoma, lymphatic invasion, neural invasion, intestinal obstruction and/or perforation by the cancer, dissection of $<13$ lymph nodes, and high preoperative serum CEA levels (10-12). Although we identified three risk factors for recurrence of stage III colorectal cancer by multivariate analysis, some factors were not risk factors for recurrence ( $\mathrm{T}$ category; $p=0.068$, histological differentiation; $p=0.119$, lymphatic invasion; $p=0.870$, venous invasion; $p=0.153)$. $\mathrm{T}$ factor 
Table II. Univariate analysis of background factors and recurrence.

\begin{tabular}{|c|c|c|c|c|}
\hline \multirow[t]{2}{*}{ Factor } & \multicolumn{2}{|c|}{ Recurrence } & \multirow{2}{*}{$\begin{array}{l}\text { Rate of } \\
\text { recurrence } \\
\quad(\%)\end{array}$} & \multirow{2}{*}{$e^{p \text {-Value }}$} \\
\hline & $\begin{array}{c}\text { Yes } \\
(\mathrm{n}=65)\end{array}$ & $\begin{array}{c}\text { No } \\
(\mathrm{n}=166)\end{array}$ & & \\
\hline \multicolumn{5}{|l|}{ Age } \\
\hline$>75$ & 52 & 138 & 27.4 & 0.575 \\
\hline$\leq 75$ & 13 & 28 & 31.7 & \\
\hline \multicolumn{5}{|l|}{ Gender } \\
\hline Male & 41 & 105 & 28.1 & 0.98 \\
\hline Female & 24 & 61 & 28.2 & \\
\hline \multicolumn{5}{|c|}{ Site of primary tumor } \\
\hline Colon & 29 & 105 & 21.6 & 0.01 \\
\hline Rectum & 36 & 61 & 37.1 & \\
\hline \multicolumn{5}{|c|}{ Surgical procedure } \\
\hline Open & 48 & 93 & 34 & 0.012 \\
\hline Laparoscopic & 17 & 73 & 18.9 & \\
\hline \multicolumn{5}{|l|}{ CEA $(\mathrm{ng} / \mathrm{ml})$} \\
\hline$\leq 5$ & 25 & 95 & 20.8 & 0.01 \\
\hline$>5$ & 40 & 71 & 36 & \\
\hline \multicolumn{5}{|l|}{ CA19-9 (U/ml) } \\
\hline$\leq 37$ & 48 & 146 & 24.7 & 0.009 \\
\hline$>37$ & 17 & 20 & 45.9 & \\
\hline \multicolumn{5}{|c|}{ Adjuvant chemotherapy } \\
\hline Yes & 50 & 125 & 28.6 & 0.47 \\
\hline No & 15 & 41 & 26.8 & \\
\hline \multicolumn{5}{|l|}{$\mathrm{T}$ category } \\
\hline$\leq \mathrm{T} 3$ & 58 & 131 & 30.7 & 0.068 \\
\hline$>\mathrm{T} 3$ & 7 & 35 & 16.7 & \\
\hline \multicolumn{5}{|c|}{ Histological differentiation } \\
\hline Tub & 54 & 153 & 26.1 & \\
\hline Muc & 4 & 4 & 50 & 0.119 \\
\hline Other & 7 & 9 & 43.8 & \\
\hline \multicolumn{5}{|c|}{ Number of metastatic lymph nodes } \\
\hline$\leq 3$ & 38 & 134 & 22.1 & 0.001 \\
\hline$>3$ & 27 & 32 & 45.8 & \\
\hline \multicolumn{5}{|l|}{ Venous invasion } \\
\hline Yes & 49 & 109 & 31 & 0.153 \\
\hline No & 16 & 57 & 21.9 & \\
\hline \multicolumn{5}{|c|}{ Lymphatic invasion } \\
\hline Yes & 50 & 126 & 28.4 & 0.87 \\
\hline No & 15 & 40 & 27.3 & \\
\hline
\end{tabular}

CEA: Carcinoembryonic antigen; CA19-9: Carbohydrate antigen 19-9; Tub: tubular adenocarcinoma; Muc: mucinous adenocarcinoma.

which is listed as one of the high recurrence risk factors of stage II by ASCO and the European Society for Medical Oncology did not show a significant difference, but a tendency may be observed because of the p-value of 0.068 . Serum CEA levels are also reported to correlate with both $\mathrm{T}$ category and positive lymph node numbers in colon cancer (13). Although T category in the current study did not show a significant difference as a risk factor for recurrence, serum CEA levels and the number of metastatic lymph nodes were identified as risk factors. This result does not seem to contradict previous reports. In the case of rectal cancer, high
Table III. Multivariate analysis for Stage III colorectal cancer

\begin{tabular}{llll}
\hline & Odds ratio & $95 \%$ CI & $p$-Value \\
\hline Rectal cancer & 2.372 & $1.269-4.433$ & 0.007 \\
CEA $(\mathrm{ng} / \mathrm{ml})>5$ & 2.02 & $1.070-3.811$ & 0.03 \\
More than 3 metastatic lymph nodes & 2.89 & $1.479-5.646$ & 0.002 \\
\hline
\end{tabular}

CEA: Carcinoembryonic antigen.

preoperative serum CEA levels have been reported as a poor prognostic factor and a risk factor for recurrence (14). As to the risk factor of lymph node metastasis for stage III colorectal cancer in the current study, TNM classification of UICC classifies three or fewer regional lymph node metastases as $\mathrm{N} 1$ and more than three metastatic lymph nodes as N2 (15). As our results indicate, the classification based on the number of lymph node metastases is very meaningful in considering the risk of recurrence.

In the current study, the recurrence rate of cases that had no risk factors was only $10.0 \%$ (5/50), which was better than the recurrence rate of $13.3 \%$ of the Japanese Society for Cancer of the Colon and Rectum for patients with stage II colorectal cancer (9). Therefore, even among stage III colorectal cancer, some cases may not require the use of LOHP as adjuvant chemotherapy or may not even need any adjuvant chemotherapy. These risk factors seem to be important to establish a postoperative treatment strategy.

The limitation of this study includes its retrospective nature and it being a study at a single center. In the future, prospective clinical trials on adjuvant chemotherapy based on the risk factors for recurrence in patients with stage III cancer are required.

\section{Conclusion}

For stage III colorectal cancer, risk factors for recurrence after curative resection consisted of rectal cancer, high preoperative serum CEA levels, and more than three metastatic lymph nodes, which may help cost-effective reduction of patients who benefit from adjuvant chemotherapy.

\section{Conflicts of Interest}

The Authors have no conflict of interest to declare regarding this study.

\section{Authors' Contributions}

Kai Neki designed the study, wrote the initial draft of the manuscript and analysis and interpretation of data. All other Authors have contributed to data collection and interpretation, and critically reviewed the manuscript. All Authors approved the final version of 
the manuscript and agree to be accountable for all aspects of the work in ensuring that questions related to the accuracy or integrity of any part of the work are appropriately investigated and resolved.

\section{References}

1 André T, Boni C, Mounedji-Boudiaf L, Navarro M, Tabernero J, Hickish T, Topham C, Zaninelli M, Clingan P, Bridgewater J, Tabah-Fisch I and de Gramont A: Oxaliplatin, fluorouracil, and leucovorin as adjuvant treatment for colon cancer. N Engl J Med 350(23): 2343-2351, 2004. PMID: 15175436. DOI: 10.1056/ NEJMoa032709

2 Kuebler JP, Wieand HS, O'Connell MJ, Smith RE, Colangelo LH, Yothers G, Petrelli NJ, Findlay MP, Seay TE, Atkins JN, Zapas JL, Goodwin JW, Fehrenbacher L, Ramanathan RK, Conley BA, Flynn PJ, Soori G, Colman LK, Levine EA, Lanier $\mathrm{KS}$ and Wolmark N: Oxaliplatin combined with weekly bolus fluorouracil and leucovorin as surgical adjuvant chemotherapy for stage II and III colon cancer: results from NSABP C-07. J Clin Oncol 25(16): 2198-2204, 2007. PMID: 17470851. DOI: 10.1200/JCO.2006.08.2974

3 André T, Boni C, Navarro M, Tabernero J, Hickish T, Topham C, Bonetti A, Clingan P, Bridgewater J, Rivera F and de Gramont A: Improved overall survival with oxaliplatin, fluorouracil, and leucovorin as adjuvant treatment in stage II or III colon cancer in the MOSAIC trial. J Clin Oncol 27(19): 3109-3116, 2009. PMID: 19451431. DOI: 10.1200/JCO.2008. 20.6771

4 Yothers G, O'Connell MJ, Allegra CJ, Kuebler JP, Colangelo $\mathrm{LH}$, Petrelli $\mathrm{NJ}$ and Wolmark N: Oxaliplatin as adjuvant therapy for colon cancer: updated results of NSABP C-07 trial, including survival and subset analyses. J Clin Oncol 29(28): 3768-3774, 2011. PMID: 21859995. DOI: 10.1200/JCO.2011.36.4539

5 Haller DG, Tabernero J, Maroun J, de Braud F, Price T, Van Cutsem E, Hill M, Gilberg F, Rittweger K and Schmoll HJ: Capecitabine plus oxaliplatin compared with fluorouracil and folinic acid as adjuvant therapy for stage III colon cancer. J Clin Oncol 29(11): 1465-1471, 2011. PMID: 21383294. DOI: 10.120 0/JCO.2010.33.6297

6 Lembersky BC, Wieand HS, Petrelli NJ, O'Connell MJ, Colangelo LH, Smith RE, Seay TE, Giguere JK, Marshall ME, Jacobs AD, Colman LK, Soran A, Yothers G and Wolmark N: Oral uracil and tegafur plus leucovorin compared with intravenous fluorouracil and leucovorin in stage II and III carcinoma of the colon: results from National Surgical Adjuvant Breast and Bowel Project Protocol C-06. J Clin Oncol 24(13): 2059-2064, 2006. PMID: 16648506. DOI: 10.1200/JCO. 2005.04.7498

7 Twelves C, Wong A, Nowacki MP, Abt M, Burris H 3rd, Carrato A, Cassidy J, Cervantes A, Fagerberg J, Georgoulias V, Husseini F, Jodrell D, Koralewski P, Kröning H, Maroun J, Marschner N, McKendrick J, Pawlicki M, Rosso R, Schüller J, Seitz JF, Stabuc B, Tujakowski J, Van Hazel G, Zaluski J and Scheithauer W: Capecitabine as adjuvant treatment for stage III colon cancer. N Engl J Med 352(26): 2696-2704, 2005. PMID: 15987918. DOI: 10.1056/NEJMoa043116
8 Shimada Y, Hamaguchi T, Mizusawa J, Saito N, Kanemitsu Y, Takiguchi N, Ohue M, Kato T, Takii Y, Sato T, Tomita N, Yamaguchi S, Akaike M, Mishima H, Kubo Y, Nakamura K, Fukuda H and Moriya Y: Randomised phase III trial of adjuvant chemotherapy with oral uracil and tegafur plus leucovorin versus intravenous fluorouracil and levofolinate in patients with stage III colorectal cancer who have undergone Japanese D2/D3 lymph node dissection: final results of JCOG0205. Eur J Cancer 50(13): 2231-2240, 2014. PMID: 24958736. DOI: 10.1016/ j.ejca.2014.05.025

9 Watanabe T, Itabashi M, Shimada Y, Tanaka S, Ito Y, Ajioka Y, Hamaguchi T, Hyodo I, Igarashi M, Ishida H, Ishihara S, Ishiguro M, Kanemitsu Y, Kokudo N, Muro K, Ochiai A, Oguchi M, Ohkura Y, Saito Y, Sakai Y, Ueno H, Yoshino T, Boku N, Fujimori T, Koinuma N, Morita T, Nishimura G, Sakata Y, Takahashi K, Tsuruta O, Yamaguchi T, Yoshida M, Yamaguchi N, Kotake K and Sugihara K: Japanese Society for Cancer of the Colon and Rectum (JSCCR) Guidelines 2014 for treatment of colorectal cancer. Int J Clin Oncol 20(2): 207-239. 2015. PMID: 26811110. DOI: $10.1007 / \mathrm{s} 10147-015-0801-\mathrm{z}$

10 Chau I and Cunningham D: Adjuvant therapy in colon cancer-what, when and how? Ann Oncol 17(9): 1347-1359, 2006. PMID: 16524974. DOI: 10.1093/annonc/md1029

11 Benson AB 3rd, Schrag D, Somerfield MR, Cohen AM, Figueredo AT, Flynn PJ, Krzyzanowska MK, Maroun J, McAllister P, Van Cutsem E, Brouwers M, Charette and M, Haller DG: American Society of Clinical Oncology recommendations on adjuvant chemotherapy for stage II colon cancer. J Clin Oncol 22(16): 3408-3419, 2004. PMID: 15199 089. DOI: $10.1200 / \mathrm{JCO} .2004 .05 .063$

12 Van Cutsem E and Oliveira J; ESMO Guidelines Working Group: Primary colon cancer: ESMO clinical recommendations for diagnosis, adjuvant treatment and follow-up. Ann Oncol 20: 49-50, 2009. PMID: 19454461. DOI: 10.1093/annonc/mdp126

13 Ma CJ, Hsieh JS, Wang WM, Su YC, Huang CJ, Huang TJ and Wang JY: Multivariate analysis of prognostic determinants for colorectal cancer patients with high preoperative serum CEA levels: prognostic value of postoperative serum CEA levels. Kaohsiung J Med Sci 22(12): 604-609, 2006. PMID: 17116621. DOI: $10.1016 / \mathrm{S} 1607-551 \mathrm{X}(09) 70360-2$

14 Tarantino I, Warschkow R, Worni M, Merati-Kashani K, Köberle D, Schmied BM, Müller SA, Steffen T, Cerny T and Güller U: Elevated preoperative CEA is associated with worse survival in stage I-III rectal cancer patients. Br J Cancer 107(2): 266-274, 2012. PMID: 25790189. DOI: 10.1038/bjc.2012.267

15 Bertero L, Massa F, Metovic J, Zanetti R, Castellano I, Ricardi U, Papotti M and Cassoni P: Eighth Edition of the UICC Classification of Malignant Tumours: an overview of the changes in the pathological TNM classification criteria: What has changed and why? Virchows Arch Sug 472(4): 519-531, 2018. PMID: 29209757. DOI: 10.1007/s00428-017-2276-y

Received August 14, 2019

Revised August 26, 2019

Accepted August 28, 2019 